\title{
A Supply and Demand Approach to Modeling Annual Reproductive and Vegetative Growth of Deciduous Fruit Trees
}

\author{
Theodore M. DeJong and Yaffa L. Grossman \\ Department of Pomology, University of California, Davis, CA 95616
}

An approach to developing a simulation model of the annual $\mathrm{C}$ supply and demand for reproductive and vegetative growth in peach trees is presented. This modeling approach simulates photosynthetic $\mathrm{C}$ assimilation using seasonal canopy light interception and daily minimum and maximum temperature and solar radiation inputs. Simulating $\mathrm{C}$ partitioning and crop growth is based on the hypothesis that plants grow as collections of semi-autonomous, but interacting, organs. The plant genotype, triggered by internal and environmental signals, determines current organ-specific growth potentials. Daily environmental conditions interact with organ-specific growth potentials to determine the conditional growth capacity and maintenance respiration requirement (i.e., the daily $\mathrm{C}$ demand) of each organ type. Then, the daily $\mathrm{C}$ available for growth after maintenance requirements are met is partitioned to leaves, fruit, stems, and branches based on their relative conditional growth capacities. Remaining carbohydrate is partitioned to the trunk, based on its conditional growth capacity, and all residual carbohydrate is partitioned to roots after aboveground demands are met. The methods used to determine organ-specific growth potentials and the usefulness of using the supply and demand approach to modeling the $\mathrm{C}$ economy of deciduous fruit crops are discussed.

The relatively intensive management requirements of perennial horticultural crops probably offer more opportunities for practical applications of computer simulation models of crop growth and carbohydrate requirements than less intensively managed annual or biennial agronomic crops. However, there has been much less research on models for perennial horticultural crops than for annual and

We gratefully acknowledge the staff of Kearney Agricultural Center for horticultural operations and field assistance. The description of the model was adapted from a $\mathrm{PhD}$ dissertation by Y.L.G. The cost of publishing this paper was defrayed in part by the payment of page charges. Under postal regulations, this paper therefore must be hereby marked advertisement solely to indicate this fact. biennial crop species because the traditional approaches used for annual row crops, such as sequential harvests of total plant biomass, present a monumental task for tree crops. Furthermore, the many management variables (such as scion cultivars, rootstock cultivars, tree spacing, location, pruning, and training) and the normal environmental variables (such as daily photon flux, temperature, water availability, and fertility) make the value of spending large amounts of time and energy to collect site-specific data for a model questionable.

However, deciduous tree crops offer certain advantages for developing functionally based simulation models that are useful for studying whole-plant $\mathrm{C}$ partitioning. Since deciduous tree crops such as peach (Prunus persica L. Batsch), plum (Prunus spp.), or apple (Malus spp.) begin the growing season with synchronized bloom, the crop load can be manipulated without stimulating further reproductive development such as subsequent bloom or increased seed number. Also, the indeterminate nature of these plants means that there is no preset normal growth or $\mathrm{C}$ partitioning pattern as there may be in rapidly developing annual plants such as cereals or grain legumes. These factors led to our development of a simulation model based on organ-specific growth potentials.

\section{Conceptual approach}

Our modeling approach is based on fundamental supply and demand principles. Carbohydrate is the basic currency of the model. For the first 150 degree-days ( 2 to 3 weeks with $7 \mathrm{C}$ minimum and $35 \mathrm{C}$ maximum thresholds) of the growing season, carbohydrate is assumed to come from storage. After that period, the daily carbohydrate supply is determined by a canopy photosynthesis submodel, SUCROS ' 86 (van Keulen et al., 1982, van Kraalingen and Spitters, 1986), that has been modified to account for the discontinuous canopy and leaf characteristics of peach orchards. The output of the C supply model is a daily estimate of the amount of carbohydrate available for structural and storage growth and maintenance of all organ types (Fig. 1).

\section{CARBON SUPPLY MODEL}

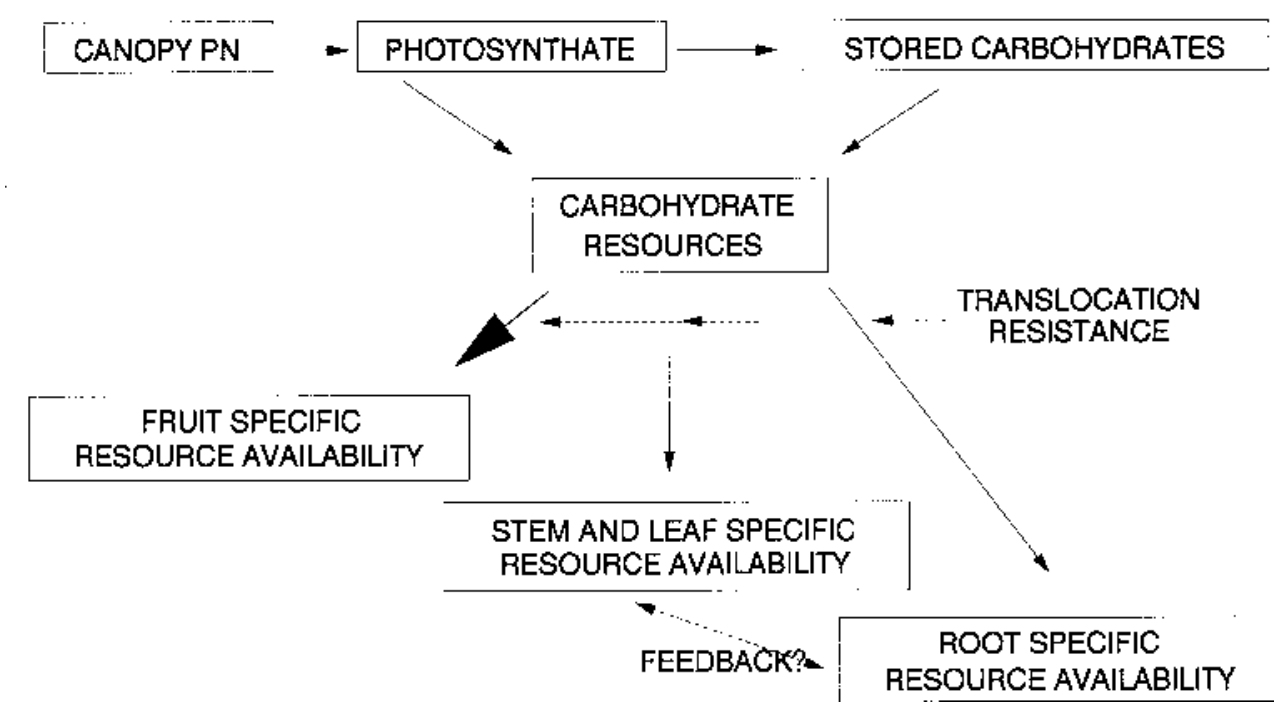

Fig. 1. A diagram of the $\mathrm{C}$ sources available to growing organs. The carbohydrate available for growth and maintenance of each organ type is determined by daily net photosynthesis, stored carbohydrate mobilization, translocation resistances between sources and sinks, and the relative competitive ability of the sinks for carbohydrates (DeJong and Grossman, 1992). 
Our approach to modeling carbohydrate use in deciduous tree crops is based on the observation that plant growth occurs in individual plant organs, including fruit, stems, leaves, and roots (Sprugel et al., 1991; Watson and Casper, 1984). With this approach, the daily carbohydrate demand is determined by the collective growth potentials of all individual growing organs on the tree. Observed carbohydrate partitioning is assumed to result from the dynamic equilibrium achieved by competition of individual sink organs for resources (Patrick, 1991) within constraints dictated by plant genotype, environmental thresholds, and ambient environmental conditions (Fig. 2). Competition between growing organs is mediated by the effect that growth has on resource availability and the relative ability of the translocation system to provide carbohydrates to the growing organs.

Although actual organ growth potentials are nearly impossible to determine experimentally, they can be estimated by measuring organ growth in response to crop load manipulation in species that may produce heavy crops naturally. In our work, we assume that measurements of individual fruit growth on trees that have had their initial crop load reduced by $\approx 90 \%$ are reasonable approximations of the potential fruit growth rate under the given environmental circumstances. Similarly, measurements of leaf, branch, and trunk growth of defruited trees are assumed to be adequate approximations of the growth potential of these organs relative to their growth potential with normal crop loads.

Respiration costs are dealt with in two ways. Maintenance respiration costs are assumed to have the highest priority for available $\mathrm{C}$ (Crapo and Ketellaper, 1981) and estimated maintenance respiration costs are met before any growth occurs. Growth respiration costs are calculated with dry-weight growth costs of the various organs.

\section{THE MODEL}

Carbohydrate supply. A diagram of the current version of the model is shown in Fig. 3, and details of the model and the computer program for the model are available in Grossman and DeJong (1994b). Daily $\mathrm{C}$ assimilation is calculated with a modified annual crop growth model, SUCROS '86 (Simple and Universal crop growth simulator) (van Keulen et al., 1982; van Kraalingen and Spitters, 1986), that explicitly simulates total daily canopy photosynthesis using Gaussian integration of the instantaneous leaf photosynthesis rate over canopy depth and diurnal light conditions (Goudriaan, 1986; Kropff et al., 1987).
The assimilation module of SUCROS ' 86 was modified to account for the discontinuous canopy in a peach orchard. The effective leaf area index during the day is adjusted using data on the daily pattern of light interception within peach orchards (DeJong and Goudriaan, 1989b). The light-saturated instantaneous photosynthetic rate is adjusted for the effect of air temperature (Y.L. Grossman, unpublished data), leaf age (DeJong and Doyle, 1984), and light exposure with canopy depth (DeJong and Doyle, 1985). Leaf area index is calculated from simulated leaf weight using an experimentally determined average specific leaf area (Y.L. Grossman, unpublished data).

Carbohydrate demand. The two components of carbohydrate demand, growth and respiration, are simulated daily. Maintenance respiration, the respiration associated with the upkeep of existing plant structures that is required for their persistence (Penning de Vries, 1975), is simulated explicitly. The carbohydrate requirement for growth is derived from the genetic potential for growth of each organ type, including the carbohydrate converted to dry matter and the respiratory cost of the conversion (Penning de Vries et al., 1974; Penning de Vries and van Laar, 1982).

Maintenance respiration cannot be experimentally separated from growth respiration on growing tissues. Several methods for distinguishing between maintenance and growth respiration have been developed (Amthor, 1989). In the mature-tissue method, maintenance respiration is estimated on a tissue that is no longer growing. In the regression method, the relationship between respiration rate and growth rate is measured, and respiration rate is extrapolated back to the point of no growth.

Leaf maintenance respiration rates were estimated from previously determined leaf-specific respiration rates using the mature-tissue method (Grossman and DeJong, 1994a). Stem, branch, and trunk maintenance respiration rates at $20 \mathrm{C}$ were estimated using the regression method:

$\mathrm{R}_{\mathrm{S}}=\mathrm{R}_{\mathrm{M}}+(\mathrm{G} * \mathrm{RGR})$

where $R_{S}$ is the specific respiration rate (grams of carbohydrate per gram dry weight per second), $R_{M}$ is the maintenance respiration rate (grams of carbohydrate per gram dry weight per second), $G$ is the growth respiration coefficient (grams of carbohydrate per gram dry weight), and RGR is the relative growth rate (grams dry weight per gram dry weight per second). $\mathrm{G}$ for peaches $(0.211 \mathrm{~g}$ carbohydrate $/ \mathrm{g}$ dry weight) was used in the calculation (DeJong and Goudriaan,

\section{SINK DEMAND MODEL}

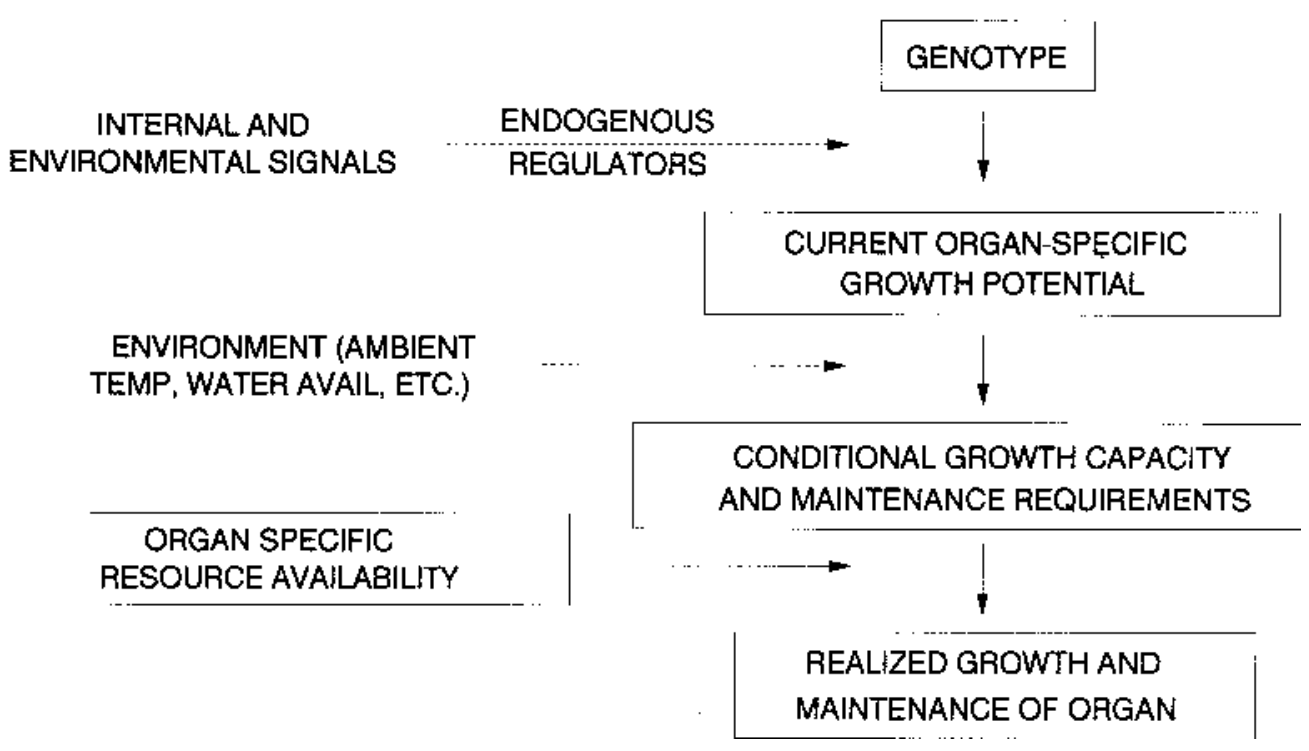

Fig. 2. A diagram of the potential and realized growth of an organ. Solid arrows indicate mechanisms, dotted arrows indicate information transfer (DeJong and Grossman, 1992). 


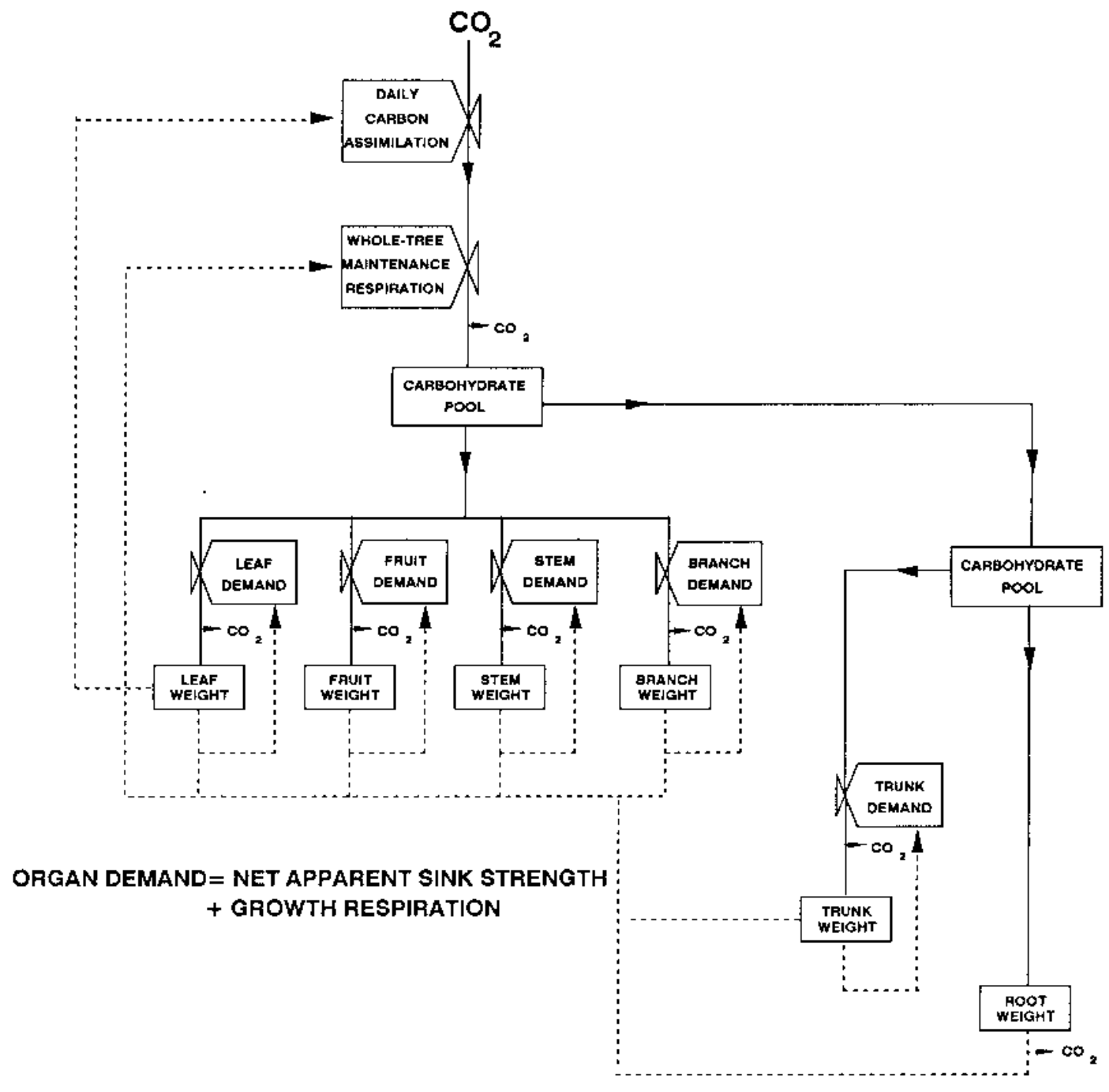

Fig. 3. Relational diagram illustrating $\mathrm{C}$ flow in the model. Boxes are state variables and valves are rate variables. Solid lines represent $\mathrm{C}$ flow and dashed lines represent information flow (Grossman and DeJong, 1994b).

1989a). Current-year stems, branches, and trunk specific respiration rates $\left(R_{S} s\right)$ and relative growth rates (RGRs) were obtained experimentally as previously described (Grossman, 1993; Grossman and DeJong,1994a). The fruit maintenance respiration rate was determined from DeJong and Goudriaan (1989a). The maintenance respiration rate for roots was set to the rate determined for branches of similar size.

Maintenance respiration is sensitive to temperature, approximately doubling when temperature increases from 20 to $30 \mathrm{C}$ (Grossman and DeJong, 1994a). For this reason, the model calculates temperature and maintenance respiration hourly. Hourly temperature is calculated from air and soil minimum and maximum temperatures assuming a sinusoidal temperature pattern during the day and an exponential temperature decline during the night (van Kraalingen and Rappoldt, 1987). The daily carbohydrate cost of maintenance respiration is determined as the sum of the products of the hourly respiration rates and the dry weights for each organ type.

The model determines daily potential net sink strength for each organ type from the seasonal patterns of organ growth potential (Grossman, 1993). The daily conditional net sink strength, reflecting the effect of temperature on growth, is determined from the potential net sink strength and the number of degree-days accumulated on each day. The carbohydrate cost of daily growth is calculated as the sum of the carbohydrate equivalent weight of the dry weight added by growth (sink strength) and the respiratory cost of that growth:
$\mathrm{C}_{\mathrm{G}}=\left(\mathrm{CE}_{\mathrm{DM}} * \mathrm{DM}\right)+(\mathrm{G} * \mathrm{DM})$

where $\mathrm{C}_{\mathrm{G}}$ is the carbohydrate cost of the dry matter added (grams of carbohydrate per day), $\mathrm{CE}_{\mathrm{DM}}$ is the carbohydrate content of the dry matter (grams of carbohydrate per gram dry weight), DM is the weight of the dry matter added (grams of dry weight per day), and G is the growth respiration coefficient (grams of carbohydrate per gram dry weight). The carbohydrate content of leaves, current-year stems, fruit, trunk, and roots was estimated from tissue $\mathrm{C}$ content measured by pyrolysis (Microanalytical Laboratory, Dept. of Chemistry, Univ. of California, Berkeley).

Carbohydrate partitioning. Carbohydrate partitioning is simulated daily. As it is generally accepted that an insufficient carbohydrate supply reduces growth before it reduces maintenance (Crapo and Ketellapper, 1981), the model supplies carbohydrate for maintenance respiration requirements before supplying carbohydrate for growth. The carbohydrate requirements for growth are satisfied based on the conditional net sink strengths of the growing organs and their proximity to the source. This approach is similar to that taken in modeling the growth of potatoes (Solanum tuberosum $\mathrm{L}$.) ( $\mathrm{Ng}$ and Loomis, 1984), grapevines (Vitis vinifera L.) (Wermelinger et al., 1991), and kiwifruit [Actinidia deliciosa (A. Chev.) C.F. Liang \& A.R. Ferguson var. deliciosa 'Hayward'] (Buwalda, 1991). All carbohydrate partitioning is characterized in terms of dry-weight gain, representing the weight of structural growth and carbohydrate storage reserves. 
The calculation of sink strength is simplified by grouping organs of the same type together, although it is recognized that transport occurs to individual growing organs. The fruit, leaves, stems, and branches are modeled as being closest to the source, followed by the trunk, and finally the roots. Daily carbohydrate availability is calculated after maintenance respiration and the carbohydrate cost of fruit, leaf, stem, and branch growth potential are calculated. Growth occurs at the potential rate if sufficient carbohydrate is available. If there is not enough carbohydrate available to support potential growth, these organs compete for carbohydrate based on their sink strength. The fraction of potential growth that can be supported is calculated as the ratio of carbohydrate available after maintenance respiration to the carbohydrate requirement for potential growth. This fraction is multiplied by the potential growth of each organ type to determine organ growth. Trunk growth is determined in the same manner by calculating the ratio of carbohydrate available after fruit, leaf, stem, and branch growth to the carbohydrate cost of trunk growth potential. Carbohydrate remaining after trunk growth supports root growth.

For the first 150 degree-days after bloom ( 2 weeks), fruit, leaves, stems, and branches are allowed to grow at their conditional growth rates, unrestricted by carbohydrate availability. The carbohydrate represented by the difference between $\mathrm{C}$ assimilation and carbohydrate required to support maintenance respiration and growth is assumed to come from stored carbohydrate and is deducted from the dry weight of the trunk and roots. During the rest of the season, carbohydrate demand is supplied only by daily $\mathrm{C}$ assimilation.

In this modeling approach, the daily $\mathrm{C}$ budget is balanced by assigning carbohydrate remaining after fruit, leaf, stem, branch, and trunk growth, and respiration demands are met to root growth. No attempt is made to account for carbohydrate loss from the roots by fine root turnover, exudation, and increased respiration during active nutrient transport. For this reason, although the model calculates root growth, the values should more reasonably be attributed to root activity, including structural and storage biomass gain and metabolic processes.

\section{MODEL SIMULATIONS}

Input data for model simulations included tree attributes (initial dry weights of fruit, leaves, stems branches, trunk, and roots; number of fruit at bloom and after thinning; thinning date) and environmental data (minimum and maximum air and soil temperatures, solar radiation).

Details concerning collecting input data, model calibration, and model accuracy are available elsewhere (Grossman, 1993; Grossman and DeJong, 1994b). We will concentrate only on demonstrating how model simulations may be used to study aspects of plant growth and development that are very difficult to study experimentally.

\section{CALIBRATION}
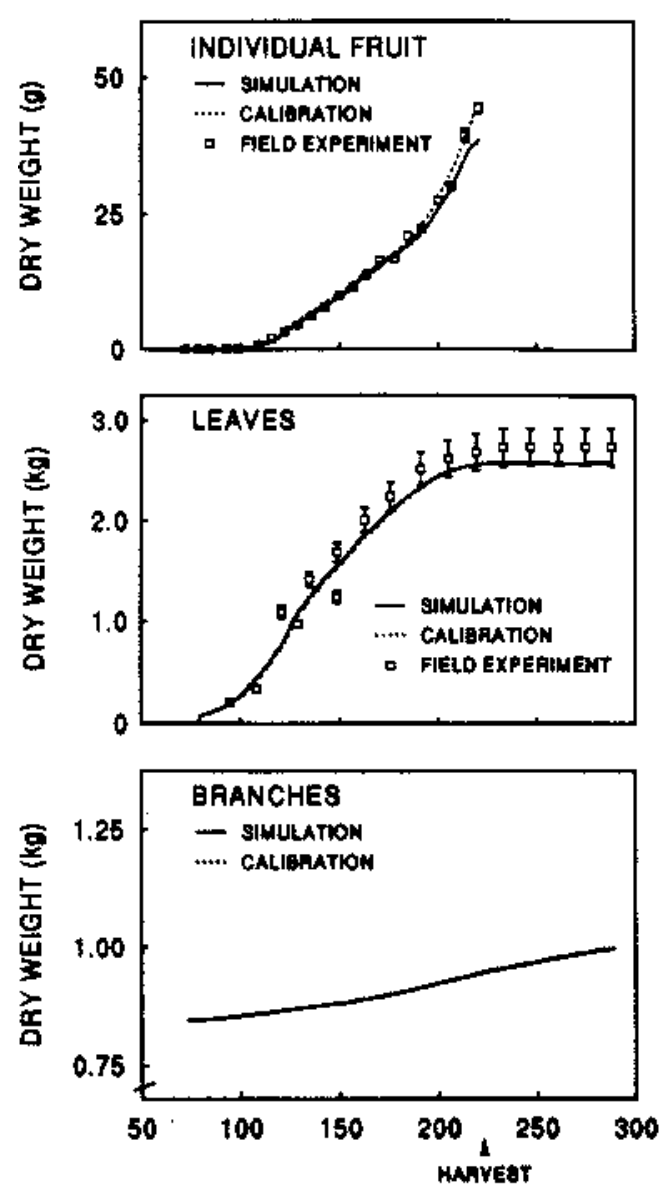
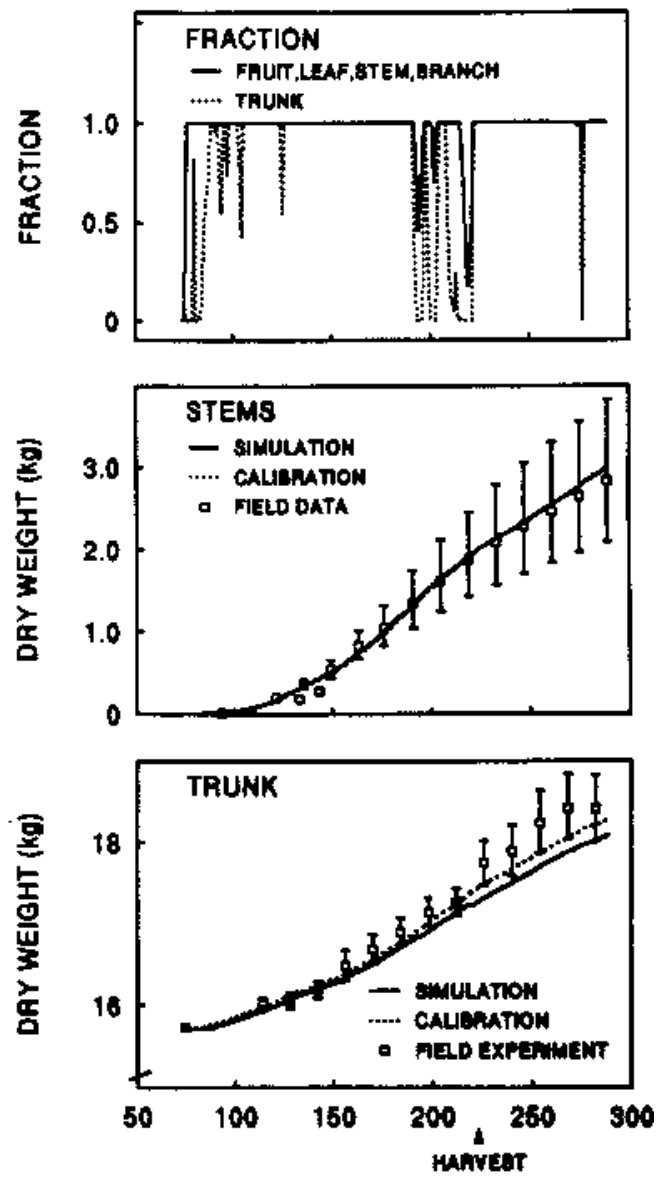

DAY OF THE YEAR

Fig. 4. Simulated, calibration, and experimental seasonal patterns of organ dry weight per tree under calibration conditions: individual fruit dry weight and the fraction of potential growth allowed by the model for peach trees that were heavily thinned at bloom, and leaf, stem, branch, and trunk dry weight per tree for defruited trees. Calibration curves for fruit and vegetative growth potentials were obtained from field data for growth on heavily thinned and defruited trees, respectively (Grossman, 1993). Calibration curves and simulation curves under calibration conditions differ because simulated carbohydrate availability restricted growth on several days. Where calibration curve is not distinguishable, it coincides with simulation curve. 


\section{THINNED AT EIGHT WEEKS}
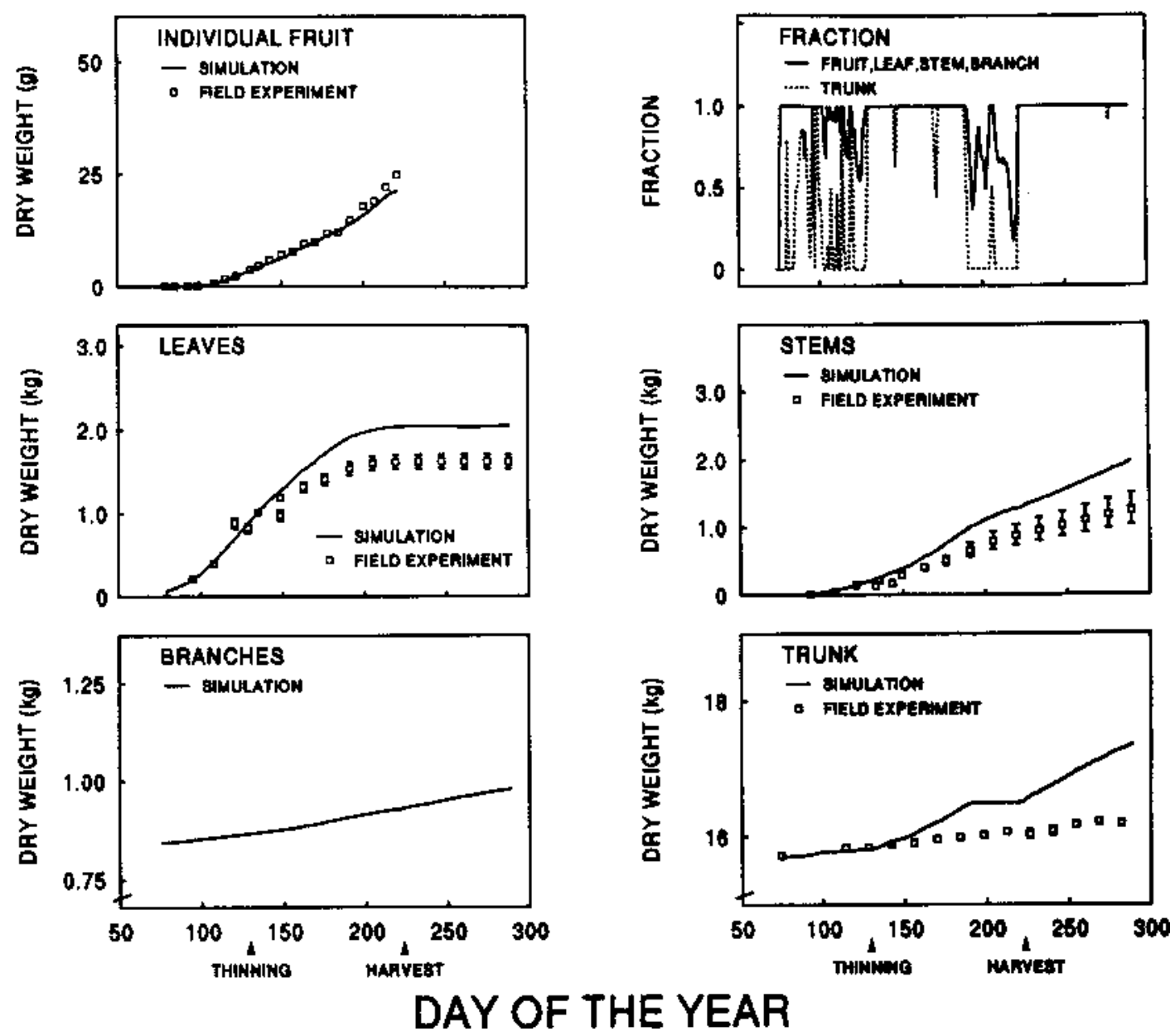

Fig. 5. Simulated and experimental seasonal patterns of individual fruit dry weight, the fraction of potential growth allowed by the model, and leaf, stem, branch, and trunk dry weight per tree for peach trees that were thinned 8 weeks after bloom (Grossman and DeJong, 1994b).

Although crop load can significantly influence vegetative drymatter production (Forshey and Elfving, 1989; Heim et al., 1979; Lenz, 1974), the timing and nature of these interactions are largely unknown. Simulations of seasonal dry-weight gain of the various plant organs and estimates of the daily carbohydrate investment costs associated with the growth of each organ (Figs. 4-6) on trees of a specific variety, crop load, and time of thinning indicate the nature of these interactions. As is generally known, fruit are the dominant sink for much of the time under normal cropping conditions. The model indicates that leaves are also a major sink during the early part of the season. The woody parts of the tree dominate the postharvest period.

Comparing simulations of organ growth under various cropping or environmental conditions allows the development of an integrated picture of the effects of changed conditions on that organ's growth (Fig. 7). This approach is particularly suitable for root activity because the model assumes that the root receives all of the residual carbohydrate available after the requirements of other organs are met. Although modeling carbohydrate partitioning to roots may overestimate root activity under certain conditions, the model clearly shows why cropping may have large effects on root growth (Heim et al., 1979; Lenz, 1974).

The model allows the calculation of quantitative estimates for daily C assimilation, respiration, and growth over the season (Fig. 8). Although these calculations depend on many assumptions and would vary greatly depending on environmental conditions, they clearly indicate the potential significance of maintenance respiration in the tree's overall C balance. They indicate seasonal C use vs. assimilation, previously unavailable for tree crops. An unusual feature of this modeling approach is that carbohydrate partitioning coefficients to the various organ types are a product of the model (Fig. 9) rather than the input since our modeling approach uses organ growth potentials as the primary determinants of carbohydrate use. In contrast, most plant simulation models partition carbohydrates according to assumed partitioning coefficients. The simulations indicate that almost all the carbohydrate is partitioned to fruit during the first few days before noticeable leaf activity begins. Then, as soon as leaf growth starts, partitioning shifts to leaf growth. The fruit regain dominance as the primary sink $\approx 1$ month later. Stems and branches receive a relatively small share of the carbohydrates until after harvest.

In retrospect, none of the results of these different types of simulations are particularly surprising. In fact, they seem to agree with many previous results and concepts regarding tree growth and crop productivity. Taken together, the modeling approach we have used describes tree and crop growth on a real-time basis and provides a conceptual basis for developing integrated working hypotheses for understanding tree function. Model predictions can be used as experimental hypotheses to be tested in the field. Alternatively, previous experimental results can be reexamined to determine if they substantiate model predictions. Furthermore, computer simulation allows dynamic integration of the effects of various input factors, such as crop load, fruit growth potential, and the environment, on tree growth and crop production. Thus, we believe that this modeling approach can be a powerful aid to developing and understanding some unifying concepts in horticultural crop production. 


\section{THINNED AT EIGHT WEEKS}
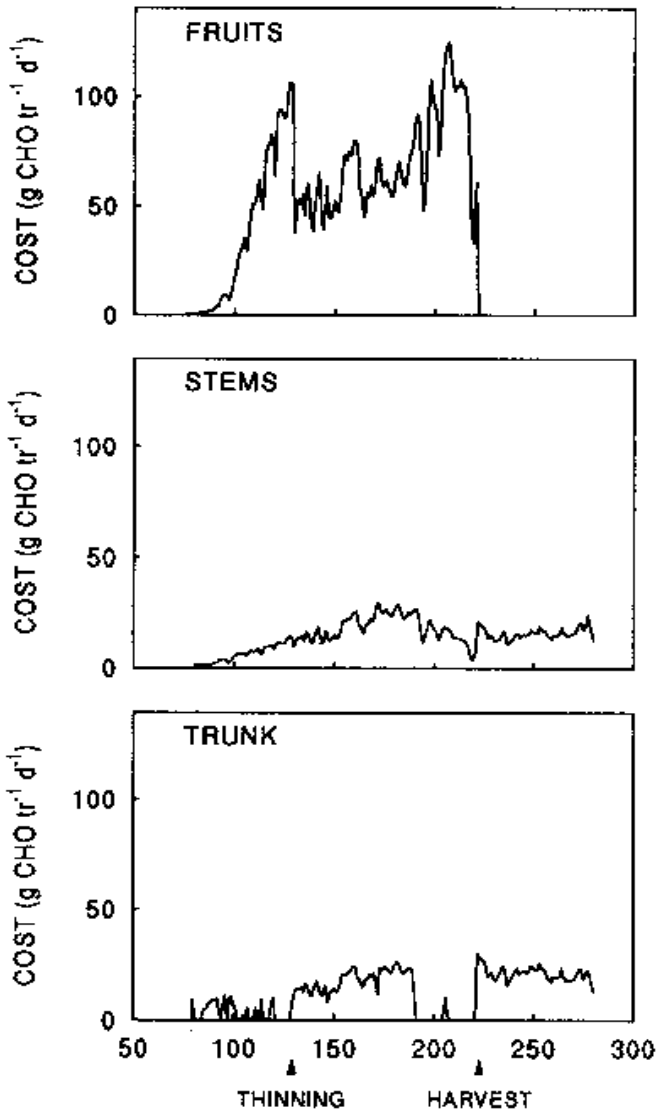
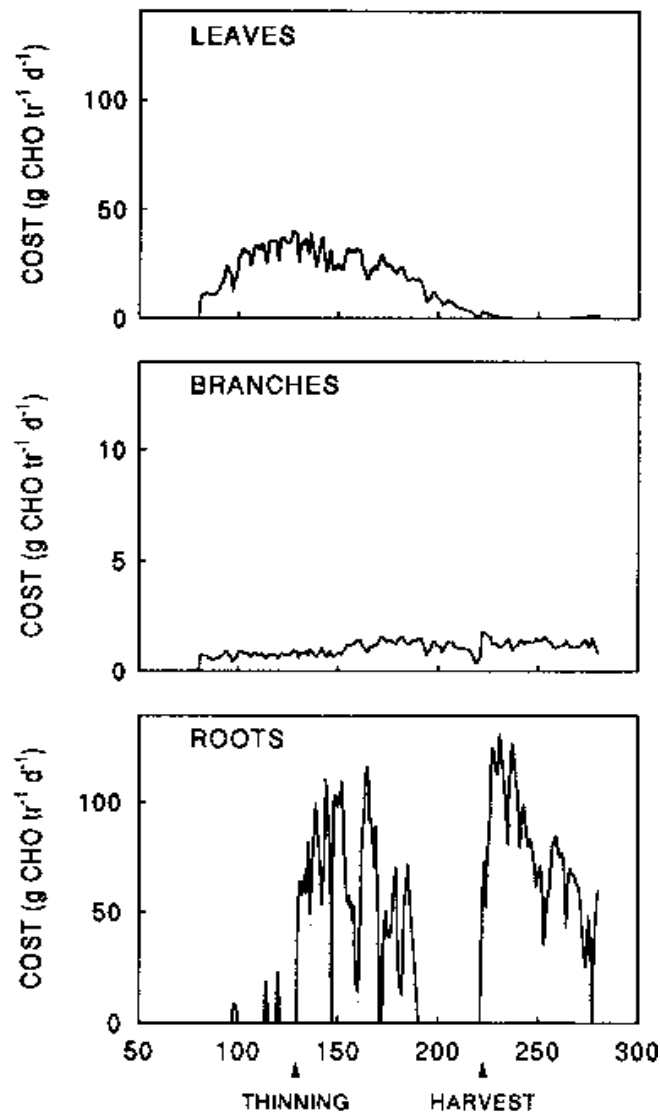

DAY OF THE YEAR

Fig. 6. Simulated seasonal patterns of daily carbohydrate investment costs of growth of fruit, leaves, stems, branches, trunk, and roots of peach trees that were thinned 8 weeks after bloom. Note scale change on graph pertaining to branches (Grossman and DeJong, 1994b).

\section{Literature Cited}

Amthor, J.S. 1989. Respiration and crop productivity. Springer-Verlag, New York. Buwalda, J.G. 1991. A mathematical model of carbon acquisition and utilization by kiwifruit vines. Ecol. Monogr. 57:43-64.

Crapo, N.L. and H.J. Ketellaper. 1981. Metabolic priorities with respect to growth and mineral uptake in roots of Hordeum, Triticum and Lycopersicon. Amer. J. Bot. 68:10-16.

DeJong, T.M. and J.F. Doyle. 1984. Leaf gas exchange and growth response of mature 'Fantasia' nectarine trees to paclobutrazol. J. Amer. Soc. Hort. Sci. 109:878-882.

DeJong, T.M. and J.F. Doyle. 1985. Seasonal relationships between leaf nitrogen content (photosynthetic capacity) and leaf canopy light exposure in peach (Prunus persica). Plant Cell Environ. 8:701-706.

DeJong, T.M. and J. Goudriaan. 1989a. Modeling peach fruit growth and carbohydrate requirements: Reevaluation of the double-sigmoid growth pattern. J. Amer. Soc. Hort. Sci. 114:800-804.

DeJong, T.M. and J. Goudriaan. 1989b. Modeling the carbohydrate economy of peach fruit growth and crop production. Acta Hort. 254:103-108.

DeJong, T.M. and Y.L. Grossman. 1992. Modeling the seasonal carbon economy of deciduous tree crops. Acta Hort. 313:21-28.

Forshey, C.G. and D.C. Elfving. 1989. The relationship between vegetative growth and fruiting in apple trees. Hort. Rev. 11:229-287.

Goudriaan, J. 1986. A simple and fast numerical method for the computation of daily totals of crop photosynthesis. Agr. For. Meteorol. 38:249-254.

Grossman, Y.L. 1993. The carbon economy of reproductive and vegetative growth of a woody perennial peach (Prunus persica (L.) Batsch): Growth potentials, respiratory demand and a simulation model. PhD Diss., Univ. of California, Davis.
Grossman, Y.L. and T.M. DeJong. 1994a. Carbohydrate requirements for dark respiration by peach vegetative organs. Tree Physiol. 14:37-48.

Grossman, Y.L. and T.M. DeJong. 1994b. PEACH: A simulation model of reproductive and vegetative growth in peach trees. Tree Physiol. 14:329345.

Heim, G., J.J. Landsberg, R.L. Watson, and P. Brain. 1979. Eco-physiology of apple trees, dry matter production and partitioning by young Golden Delicious trees in France and England. J. Applied Ecol. 126:179-194.

Kropff, M.J., L. Bastiaans, and J. Goudriaan. 1987. Implications of improvements in modeling canopy photosynthesis in SUCROS (a simple and universal crop growth simulator). Netherlands J. Agr. Sci. 35:192-194.

Lenz, F. 1974. Fruit effects on formation and distribution of photosynthetic assimilates. Proc. XIX Intl. Hort. Congr., Warsaw. p. 155-166.

$\mathrm{Ng}$, E. and R.S. Loomis. 1984. Simulation of growth and yield of the potato crop. Centre for Agricultural Publishing and Documentation, Wageningen, The Netherlands.

Patrick, J.W. 1991. Control of phloem transport to and short-distance transfer in sink regions: An overview, p. 167-177. In: J.L. Bonnemain, S. Delrot, W.J. Lucas, and J. Dainty (eds.). Recent advances in phloem transport and assimilate compartmentation. Oest Editions, Nantes, France.

Penning de Vries, F.W.T. 1975. The cost of maintenance processes in plant cells. Ann. Bot. 39:77-92.

Penning de Vries, F.W.T., A.H.M. Brunsting, and H.H. van Laar. 1974. Products, requirements and efficiency of biosynthesis: A quantitative approach. J. Theoretical Biol. 45:339-377.

Penning de Vries, F.W.T. and H.H. van Laar. 1982. Simulation of plant growth and crop production. Centre for Agricultural Publishing and Documentation, Wageningen, The Netherlands.

Sprugel, D.G., T.M. Hinckley, and W. Schaap. 1991. The theory and practice 
ROOTS
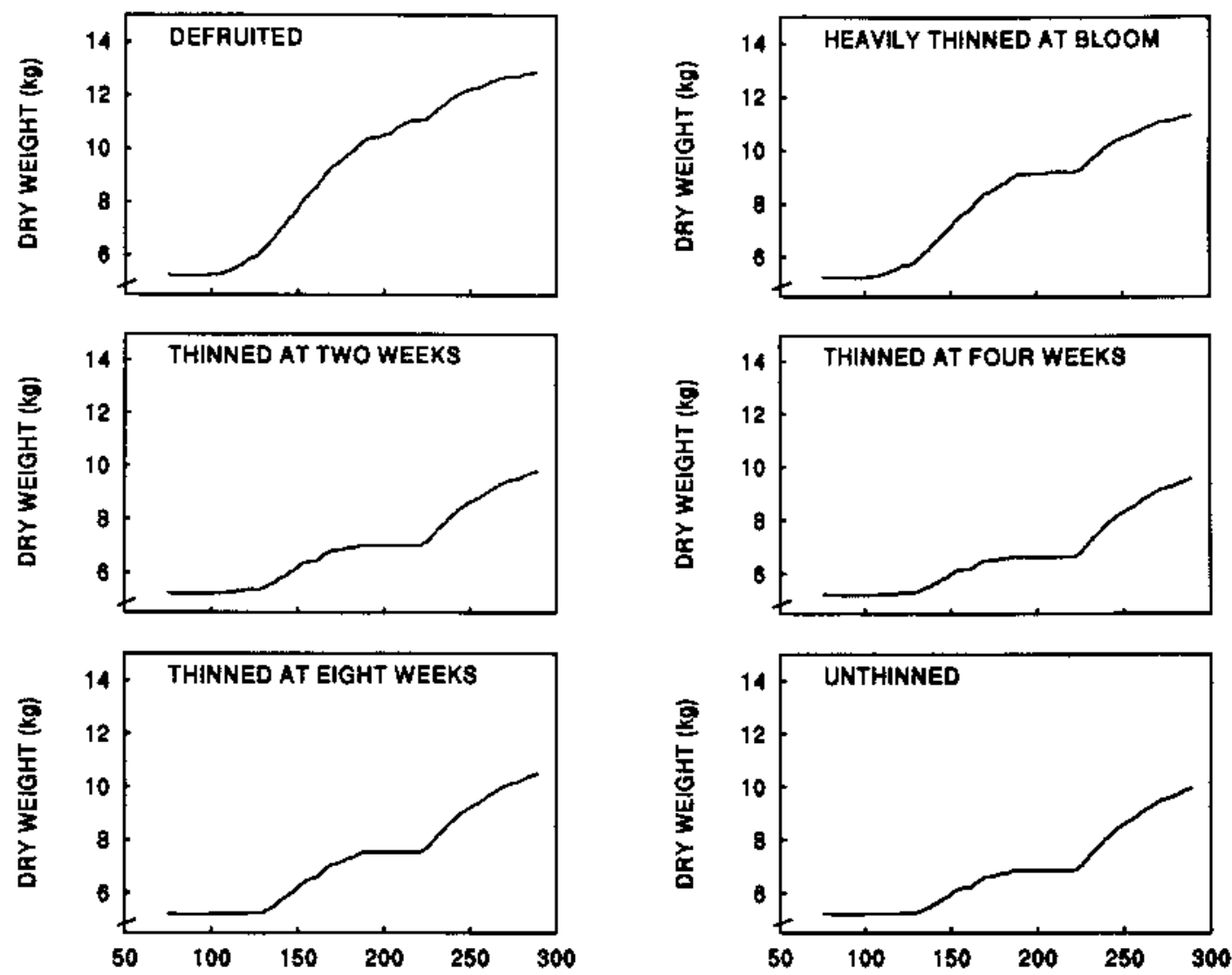

DAY OF THE YEAR

Fig. 7. Simulated seasonal pattern of dry-weight accumulation in roots per tree for peach trees that were defruited; heavily thinned at bloom; thinned 2,4 , or 8 weeks after bloom; and left unthinned (Grossman and DeJong, 1994b).

\section{SIMULATED CARBOHYDRATE SUPPLY AND DEMAND}
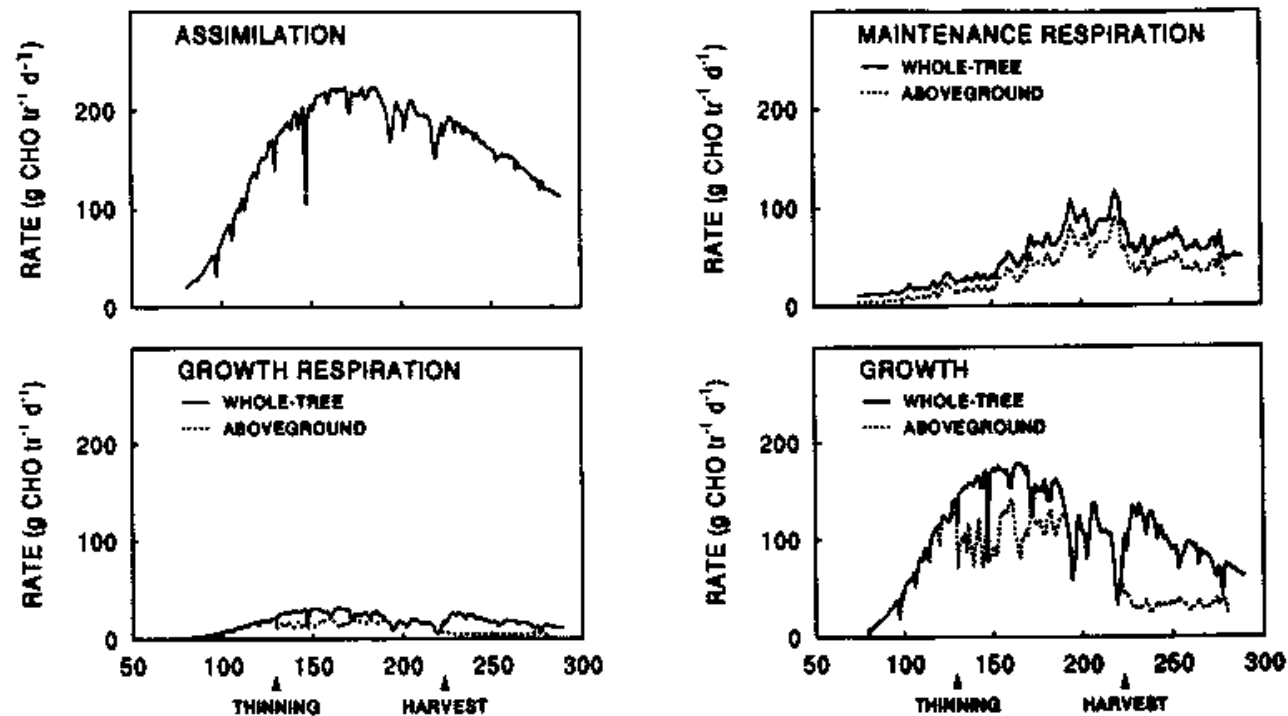

DAY OF THE YEAR

Fig. 8. Simulated seasonal pattern of daily $\mathrm{C}$ assimilation, maintenance respiration, growth respiration, and growth of peach trees that were thinned 8 weeks after bloom. Values can be converted to grams of carbohydrate per square meter per day dividing by 8 (Grossman and DeJong, 1994b). 


\section{SIMULATED PARTITIONING COEFFICIENTS}
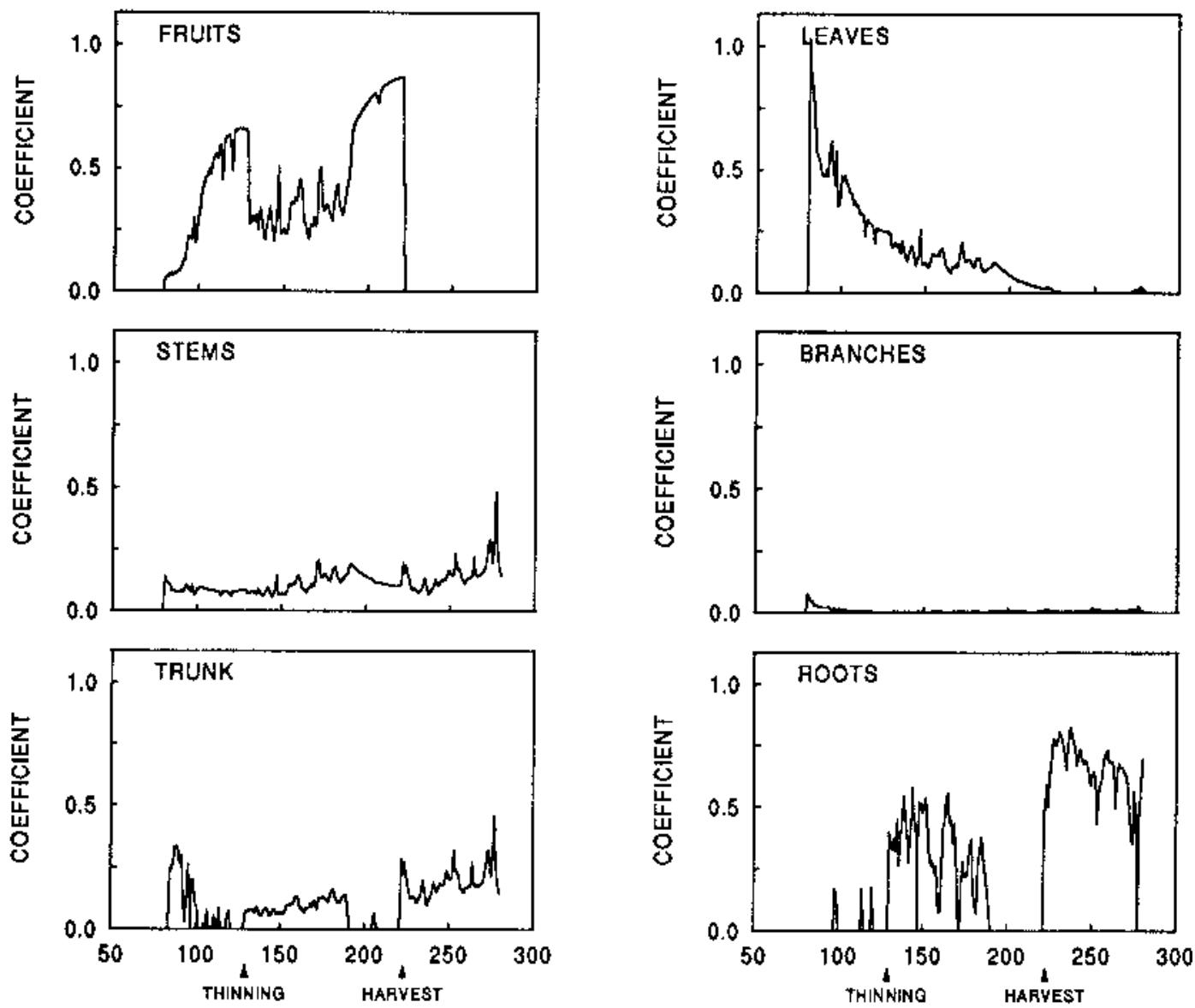

DAY OF THE YEAR

Fig. 9. Simulated seasonal patterns of the partitioning coefficients for fruit, leaves, stems, branches, trunk, and roots of peach trees that were thinned 8 weeks after bloom (Grossman and DeJong, 1994b).

of branch autonomy. Annu. Rev. Ecol. Systematics 22:309-334.

van Keulen, H., F.W.T. Penning de Vries, and E.M. Drees. 1982. A summary model for crop growth, p. 87-97. In: F.W.T. Penning de Vries and H.H. van Laar (eds.). Simulation of plant growth and crop production. Centre for Agricultural Publishing and Documentation, Wageningen, The Netherlands. van Kraalingen, D. and K. Rappoldt. 1987. Subprograms in simulation models. Internal Rpt. Center for Agrobiological Research/Dept. of Theoretical Production Ecology, Wageningen, The Netherlands. van Kraalingen, D. and C.J.T. Spitters. 1986. A simple and universal crop growth simulator: SUCROS '86. Internal Rpt. Center for Agrobiological Research/ Dept. of Theoretical Production Ecology, Wageningen, The Netherlands. Watson, M.A. and B.B. Casper. 1984. Morphogenetic constraints on patterns of carbon distribution in plants. Annu. Rev. Ecol. Systematics 15:233-258.

Wermelinger, B., J. Baumgärtner, and A.P. Gutierrez. 1991. A demographic model of assimilation and allocation of carbon and nitrogen in grapevines. Ecol. Modelling 53:1-26. 